\title{
Ontogenetic changes in swimming speed of silver carp, bighead carp, and grass carp larvae: implications for larval dispersal
}

\author{
Amy E. George ${ }^{\text {Corresp., }}{ }^{1}$, Tatiana Garcia ${ }^{2}$ ， Benjamin H. Stahlschmidt ${ }^{1}$ ， Duane C. Chapman ${ }^{1}$ \\ ${ }^{1}$ Columbia Environmental Research Center, U.S. Geological Survey, Columbia, Missouri, United States \\ 2 Illinois Water Science Center, U.S. Geological Survey, Urbana, Illinois, United States \\ Corresponding Author: Amy E. George \\ Email address: ageorge@usgs.gov
}

Bighead, silver, and grass carps are invasive in the waterways of central North America, and grass carp reproduction in tributaries of the Great Lakes has now been documented. Questions about recruitment potential motivate a need for accurate models of egg and larval dispersal. Quantitative data on swimming behaviors and capabilities during early ontogeny are needed to improve these dispersal models. We measured ontogenetic changes in routine and maximum swimming speeds of bighead, grass, and silver carp larvae. Daily measurements of routine swimming speed were taken for two weeks posthatch using a still camera and the LARVEL program, a custom image-analysis software. Larval swimming speed was calculated using larval locations in subsequent image frames and time between images. Using an endurance chamber, we determined the maximum swimming speed of larvae (post gas bladder inflation) for four to eight weeks post-hatch. For all species, larval swimming speeds showed similar trends with respect to ontogeny: increases in maximum speed, and decreases in routine speed. Maximum speeds of bighead and grass carp larvae were similar and generally faster than silver carp larvae. Routine swimming speeds of all larvae were highest before gas bladder inflation, most likely because gas bladder inflation allowed the fish to maintain position without swimming. Downward vertical velocities of pre-gas bladder inflation fish were faster than upward velocities. Among the three species, grass carp larvae had the highest swimming speeds in the pre-gas bladder inflation period, and the lowest speeds in the post gas bladder inflation period. Knowledge of swimming capability of these species, along with hydraulic characteristics of a river, enables further refinement of models of embryonic and larval drift. 
1 Ontogenetic changes in swimming speed of silver carp, bighead carp, and grass carp

2 larvae: implications for larval dispersal

3 Amy E. George ${ }^{1,3}$, Tatiana Garcia ${ }^{2}$, Benjamin H. Stahlschmidt ${ }^{1}$, Duane C. Chapman ${ }^{1}$

4

5

6

7

8

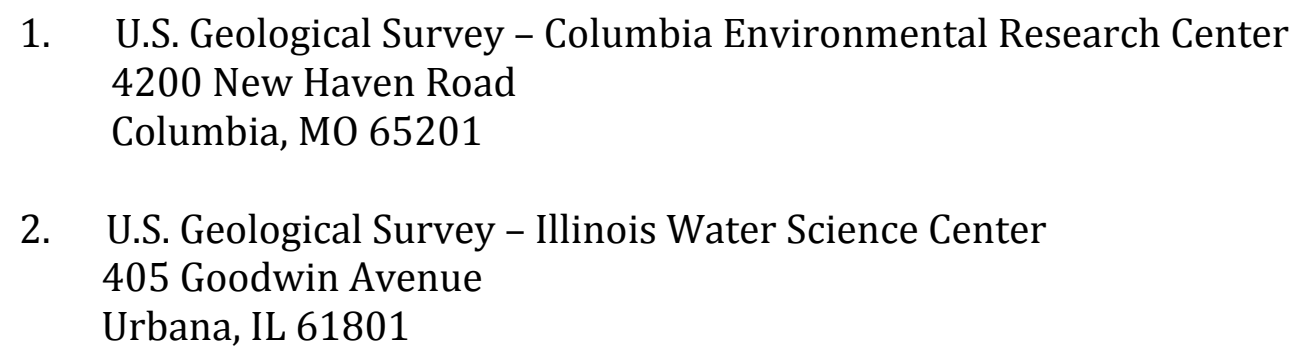

\section{3.rageorge@usgs.gov}

Short title: Swimming speeds of carp larvae

\section{Abstract}

Bighead, silver, and grass carps are invasive in the waterways of central North America, and grass carp reproduction in tributaries of the Great Lakes has now been documented. Questions about recruitment potential motivate a need for accurate models of egg and larval dispersal. Quantitative data on swimming behaviors and capabilities during early ontogeny are needed to improve these dispersal models. We measured ontogenetic changes in routine and maximum swimming speeds of bighead, grass, and silver carp larvae. Daily measurements of routine swimming speed were taken for two weeks posthatch using a still camera and the LARVEL program, a custom image-analysis software. Larval swimming speed was calculated using larval locations in subsequent image frames and time between images. Using an endurance chamber, we determined the maximum swimming speed of larvae (post gas bladder inflation) for four to eight weeks post-hatch. For all species, larval swimming speeds showed similar trends with respect to ontogeny: increases in maximum speed, and decreases in routine speed. Maximum speeds of bighead and grass carp larvae were similar and generally faster than silver carp larvae. Routine swimming speeds of all larvae were highest before gas bladder inflation, most likely because gas bladder inflation allowed the fish to maintain position without swimming. Downward vertical velocities of pre-gas bladder inflation fish were faster than upward velocities. Among the three species, grass carp larvae had the highest swimming speeds in the pre-gas bladder inflation period, and the lowest speeds in the post gas bladder inflation period. Knowledge of swimming capability of these species, along with hydraulic characteristics of a river, enables further refinement of models of embryonic and larval drift. 


\section{Introduction}

Silver carp (Hypophthalmichthys molitrix), bighead carp (H. nobilis), (together, the bigheaded carps) and grass carp (Ctenopharyngodon idella) are invasive species in the waterways of central North America. They have continued to spread into new waterways, and threaten to spread into the Laurentian Great Lakes. Prediction of recruitment potential in tributaries of the Great Lakes (Kocovsky et al. 2012; Garcia et al. 2013; Garcia et al. 2015a), and the discovery of grass carp eggs and young in the Sandusky River (Chapman et al. 2013; Embke et al. 2016) have shown the need for research into different aspects of early life history of these fishes.

The eggs of these fishes are semi-buoyant, and their survival is believed to require a length of river in which they drift downstream before hatching, and a minimum turbulence or velocity to keep the eggs from settling and being covered by sediment (Kolar et al. 2007; George et al. 2015). Previous works have often assumed the requisite river length is approximately $100 \mathrm{~km}$ and minimum velocity to be around $0.7 \mathrm{~m} / \mathrm{s}$ (Soin and Sukhanova 1972; Krykhtin and Gorbach 1981; Kolar et al. 2007; Kocovsky et al. 2012). However, because interacting physical and biological variables control the development and settling of eggs, determining the adequacy of a river for egg survival requires a model such as FluEgg (Garcia et al. 2013; Garcia et al. 2015a) which uses river physical characteristics such as temperature and turbulence combined with biological parameters such as developmental rate of the different species at different temperatures and egg sinking rates. After hatch, the larvae continue to drift for a period before they begin horizontal swimming and leave the main channel in search of nursery areas. Incorporation of the larval dispersal period into FluEgg would allow the determination of the river reaches where larvae are likely to leave the main channel, or could be used to determine the river reaches where captured larvae were spawned. Currently, larval drift dynamics are included in the FluEgg model as passive particles, by maintaining the vertical position of the larvae over time (Murphy et al. 2016). However, larval drift dynamics are more complicated than those of passive particles because of the behavior of the larvae. The swimming capabilities of larvae change during ontogeny, in a transition marked by both behavioral (from vertical swimming to horizontal swimming) and anatomical (gas bladder emergence) changes (Chapman and George 2011; George and Chapman 2013; George and Chapman 2015), that allow larvae to move laterally and hold position within the water column. Behavior, swimming kinematics, and swimming capabilities become complex factors that are seldom considered in larval dispersal or particle transport models. Much of the focus in larval behavioral work has been on marine environments (e.g. Peck et al. 2006), with comparatively few studies done on riverine species (Schludermann et al. 2012; Lechner et al. 2014). To model the likelihood of recruitment in rivers or the areas where larvae would leave the main channel, it is necessary to have measurements of swimming capability as a function of larvae developmental stage.

Routine swimming (or free swimming) speed is an aerobic form of spontaneous swimming and can help establish vulnerability to predation, and encounter rates (Muller 2008). Critical speed is a form of prolonged swimming, and is defined as the maximum velocity 
89 that a fish can maintain for a precise period of time (generally 20 minutes, though this time 90 period is species- and age-dependent), and is useful for determining vulnerability to larval 91 drift (Muller 2008). Burst speed is an anaerobic form of swimming and is usually a nearly 92 instantaneous escape reaction. Maximum speed (a form of burst swimming) can only be maintained for periods under 20 seconds (Beamish 1978). It is generally slower than burst speeds, and is often maintained for nearly the entire 20 second period, rather than having a quick initial burst of high speed followed by slower swimming or no swimming. Measurements of critical and maximum speed use the same techniques and equations, being different only in step duration. Even though short in duration, short-term high performance is necessary for predator evasion, prey capture, response to disturbance, and navigation of currents in riverine systems (Muller 2008). Rivers are hydraulically variable, with changes in flow, velocity, and turbulence occurring over depth and longitudinal profiles. Intense short-term swimming (or maximum speed) is an essential element of larval fish locomotion within these systems, and knowing the maximum speed the fish are capable of at different ontogenetic stages allows for the refinement of dispersal models if hydraulic conditions are known at relevant scales. Experiments in a laboratory flume by Prada et al. (in review) show that the swimming speed of larval grass carp is generally slower than the speed of the current, leading to downstream displacement by a current. Given this seeming behavioral constraint, critical speed becomes less predictive of potential dispersal, while maximum speed and the ability of larvae to manage shear velocity and turbulence become more important for larvae moving into lower velocity habitat.

111 Swimming speeds of adult and larger juvenile fish tend to be well documented, because 112 they are more easily measured and are subject to different forces (i.e. viscosity for larval 113 fish vs. inertial forces on larger fish; Videlier 1991). In most species of fish, absolute 114 swimming speed (m/s) increases with ontogeny, while relative swimming speed (body lengths per second; BL/s) decreases (Muller 2008). Juveniles, sub-adults and adults of grass carp and bigheaded carps have high absolute burst speeds, with lower relative burst speeds. Komarov (1971) calculated the burst speed of $27 \mathrm{~cm}$ silver carp at $9.2 \mathrm{BL} / \mathrm{s}$ or 2.48 $\mathrm{m} / \mathrm{s}$. Telemetry work suggests that sub-adult silver carp can exceed $3 \mathrm{~m} / \mathrm{s}$, but had a routine speed averaging less than $0.35 \mathrm{~m} / \mathrm{s}$ (Hoover et al. 2012). Subsequent laboratory investigations showed that large juveniles have a burst swimming speed of $0.77 \mathrm{~cm} / \mathrm{s}$, and sub-adults have burst swimming capability up to $1.28 \mathrm{~m} / \mathrm{s}$ (Hoover et al. 2012). Field tests of silver carp adults found prolonged swimming speeds of 1.09-1.23 m/s and burst speeds of 1.37-1.51 m/s or 1.9 BL/s (Hoover et al. 2016; Hoover et al. 2017). Juvenile bighead carp were found to have prolonged swimming speeds of $0.51 \mathrm{~m} / \mathrm{s}(6.81$ fork lengths per second; $\mathrm{FL} / \mathrm{s}$ ) and a burst speed of $1.22 \mathrm{~m} / \mathrm{s}$ or $12.78 \mathrm{FL} / \mathrm{s}$ (Newbold et al. 2016). While the data for adults and juveniles are primarily burst swimming speed instead of the somewhat slower maximum speed, adults and larger juveniles had lower relative speeds than larval carp (20$30 \mathrm{BL} / \mathrm{s}$ at early stages). Videler (1993) predicts burst swimming speeds for larval fish of 1 $\mathrm{cm}$ to be approximately $47 \mathrm{BL} / \mathrm{s}$, though taxonomic differences also play a large role in the development of swimming speed (Fisher and Leis 2010). As with many species, swimming capacity of bighead, silver, and grass carps during early life history is poorly documented. Chapman and George 2011 first reported observations of vertical swimming capabilities beginning shortly after hatching. Horizontal swimming begins as soon as two days after 
134 hatch (upon the emergence of the gas bladder). George and Chapman 2013 and George and

135 Chapman 2015 further reported coarsely measured vertical swimming speeds, and water

136 column location for vertical and horizontally swimming grass carp and bigheaded carp

137 larvae.

138

139

140

With little information available on swimming behavior in larval bigheaded carps or grass carp, accurate modelling of larval dispersal has been difficult. Dispersal and drift models

141

142

143

144

145

146

147

148

149 should optimally consider larval movement and swimming capabilities instead of treating larvae as neutrally buoyant particles, because behavior can have large impacts on dispersal (Failletaz et al. 2018). By including information over a range of ages, sizes, and developmental stages, models can be enhanced to predict downstream dispersal range, as well as where larvae could move into nursery habitat. A better understanding of the transport mechanisms of swimming larvae, as well as the location where grass carp and bigheaded carps start leaving the main channel, would facilitate detection and control efforts targeting the early life stages of these invasive fishes (George and Chapman 2013). Routine swimming speeds have not been reported for horizontally swimming larvae of

150

151

152

153

154

155

156 grass or bigheaded carps, and maximum swimming speeds are unknown for any early life history stages of these fishes. The role of developmental stage and larval size in swimming capacity has also not been explored for these species. Our objectives were to determine the routine and maximum swimming speeds of bigheaded carps and grass carp during the first stages of early life history, and to use these in the context of determining dispersal potential.

This study plan was approved by the Columbia Environmental Research Center Animal Care and Use Committee.

Spawning and culture information

After evaluation for spawning readiness, 2 grass carp females ( 4.2 and $5.4 \mathrm{~kg}$ ) were given an initial intramuscular injection of $200 \mathrm{IU} / \mathrm{kg}$ human chorionic growth hormone (HCG), with a second injection of $1200 \mathrm{IU} / \mathrm{kg}$ HCG given 12 hours later. A resolving dose of 8.8 $\mathrm{mg} / \mathrm{kg}$ carp pituitary was given 24 hours after the second injection. Five grass carp males $(2.3,3.3,3.5,3.6$, and $5.2 \mathrm{~kg})$ were given an $8.8 \mathrm{mg} / \mathrm{kg}$ intramuscular carp pituitary injection 12 hours prior to milt collection. A single $11.18 \mathrm{~kg}$ bighead carp female was given an initial intraperitoneal injection of $200 \mathrm{IU} / \mathrm{kg} \mathrm{HCG}$, and a resolving dose of $4.0 \mathrm{mg} / \mathrm{kg}$ carp pituitary 6 hours later, while 4 males $(9.0,9.7,10.4$ and $10.4 \mathrm{~kg}$ ) received a $4.0 \mathrm{mg} / \mathrm{kg}$

171 intraperitoneal carp pituitary injection 12 hours prior to collecting milt. Four silver carp females $(4.5,5.1,5.8$, and $6.4 \mathrm{~kg})$ received an initial intraperitoneal injection of $600 \mathrm{IU} / \mathrm{kg}$ HCG, and a resolving dose of $4 \mathrm{mg} / \mathrm{kg}$ carp pituitary 6 hours after the initial injection, while 1745 males $(3.4,3.4,3.4,3.4$, and $4.4 \mathrm{~kg})$ received a $4 \mathrm{mg} / \mathrm{kg}$ intraperitoneal injection of carp 175 pituitary 27 hours prior to expected ovulation. Milt from all three species was examined for 
176 quality and stored in beakers on ice prior to use. Stripped oocytes were fertilized with 177 pooled milt by the dry method (Piper et al. 1982) for one minute, rinsed and allowed to 178 water harden in a water bath for 30 minutes before stocking $100-200 \mathrm{~mL}$ of eggs from all 179 females of a given species into 10 modified MacDonald hatching jars. Eggs and larvae were 180 reared at constant temperatures of $22.9^{\circ} \mathrm{C}$ in tanks. Temperature was maintained through 181 the use of heaters and chillers, and monitored by HOBO temperature loggers (Onset 182 Computer Corporation; Bourne, Massachusetts). All water used was well water (carbonate 183 184

216 Images were then analyzed using software program LARVEL (available on GitHub; 217 https://github.com/tgarciabotero/LARVEL). The LARVEL program identifies the centroid

After hatch, a subset of larvae was kept in 20 gallon tanks for approximately 16 days. Following the onset of exogenous feeding (at approximately 3-4 days post hatch), larvae were fed brine shrimp twice daily. All other larvae were transferred into an $890 \mathrm{~m}^{2}$ pond at the onset of exogenous feeding. Zooplankton populations within ponds were high, based on observations of many Daphnia at the margins of the pond, and there was no supplemental feeding. Ponds were not temperature controlled and temperature was not monitored.

\section{Routine swimming speed measurements}

For routine swimming speeds, approximately 200 larvae were placed in a tank $(1 \mathrm{~m}$ in height, $0.23 \mathrm{~m}$ in length , $0.15 \mathrm{~m}$ in depth), with non-flowing water. Knema ${ }^{\circledR}$ (Shreveport, Louisiana) light panels were placed behind the tank to provide uniform illumination to facilitate photography. White plastic was used over the light panels to homogenize the background. Temperature was monitored with a handheld thermometer, and was controlled by ambient temperature. No structures that larvae could orient to were placed in the tank. The tank and lighting/camera equipment were kept in an environmental chamber (Darwin Chambers Company; St. Louis, Missouri) held at $22.5^{\circ} \mathrm{C}$, with a $16: 8$ hour day: night cycle. To minimize any diel effects on behavior, all photos were taken during daylight hours. Light intensity at the tank ranged from 500-700 lux.

Using a Nikon 7100 camera, 2 sets of 14 pictures were taken daily with camera settings detailed in Table 1. The camera settings used needed to be exact in order to effectively capture all larvae in the plane of view, while also having a fast enough shutter speed to give a crisp image of the larvae. A small grid $(1 \mathrm{~cm}$ squares, $3 \mathrm{~cm}$ wide $\mathrm{x} 10 \mathrm{~cm}$ tall) was included in all photographs for scale. The photo frame excluded the sides and bottom of the tank to avoid measuring speeds biased by the interaction with a substrate.

In most image particle tracking applications, intervals between consequent photos are extremely short, with an ideal rate of 8-9 frames per second (e.g. Garcia et al 2015b). We used 2-3 frames per second for silver carp larvae, which complicated path-tracking, but did not affect conclusions. Images for bighead carp and grass carp larvae had rates of 6-7 frames per second, which we found to provide accurate data and work within the limits of camera equipment. 
218 of the location of semi-transparent larvae in a series of consequent images using image

219 analysis techniques. Images are converted to binary, and neighboring spots within a certain

220 distance are merged to ensure capture of the correct number of larvae. Noise within the

221 user-defined frame is reduced, and the centroids of mass in subsequent images are

222 compared to identify larval movement, using particle tracking algorithms and a set of user

223 defined measurements within each set of pictures. Each individual larval path was visually

224 examined for accuracy (based on human analysis of photos) and manually corrected as

225 necessary.

\section{Maximum swimming speed}

Maximum swimming speeds were measured in swimming chambers from Loligo Systems (Viborg, Denmark; 5L capacity, chamber size $30 \mathrm{~cm} \times 8 \mathrm{~cm} \times 8 \mathrm{~cm}$; with speed control up to 60 hertz (Hz)). Temperature within the swim chamber was controlled by room temperature and ranged from $20.4-22.8^{\circ} \mathrm{C}$. After gas bladder inflation and the initiation of horizontal swimming at approximately $3-4$ days post hatch (DPH), individual daily measurements of maximum speed for 10-20 laboratory reared fish were taken for approximately 2 weeks post hatch. We took weekly measurements of maximum speed for 10-20 pond-reared fish until squamation (Stage 48; Yi et al. 1988a). Developmental time varied among the species. Fish were collected from ponds with light traps and nets (as necessary) and acclimated overnight in a tank. Care was taken to ensure that fish were in good condition and undamaged before they were used in the swim chambers.

Swimming chambers were started at relatively slow initial water velocity before fish were placed in the chamber, until the flow reached a steady state. This facilitated measurements by preventing larvae from swimming out of the chamber. Initial speed varied by developmental stage, and was always lower than slowest fish of the previous day. Water velocity was incrementally increased $(\sim 0.1 \mathrm{~Hz}$ at a time, approximately $0.218 \mathrm{~cm} / \mathrm{s})$ every two seconds until larvae could no longer hold position. With little information available about swimming capacities of these species in their larval stages, we selected a short step duration to ensure that the maximum speed determined was reflective of the actual maximum speed that a larva would be capable of swimming. Longer step durations would have increased fatigue and given measurements that were not reflective of potential speeds. Flow velocity within the Loligo swim chamber was determined using a Höntzsch flow meter at relevant hertz and a regression model was developed for all speeds (Byrd et al., in review ):

$\mathrm{U}=0.0218 \mathrm{x}-0.0731$, where $\mathrm{x}=$ frequency in $\mathrm{Hz}$, and $\mathrm{U}$ is water velocity in $\mathrm{cm} / \mathrm{s}$.

Maximum speed $\left(\mathrm{U}_{\max }, \mathrm{in} \mathrm{cm} / \mathrm{s}\right)$ is then computed using the formula:

$U_{\max }=U+\left(t / t_{i} * U_{i}\right)$, where $U=$ penultimate speed $(\mathrm{cm} / \mathrm{s}$; reported final speed -0.218$), U_{i}=$ speed increment $(\mathrm{cm} / \mathrm{s}), \mathrm{t}=$ time swim in the final speed increment $(0 \mathrm{~s})$, and $\mathrm{t}_{\mathrm{i}}=$ the time 
260 interval for each velocity increment (2 s).

261

262

263

264

265

266

267

268

269

270

271

272

273

274

275

276

277

278

279

280

281

282

283

284

285

286

287

288

289

290

291

292

293

294

295

296

297

298

299

300

Daily measurements of total length were taken for the 10-20 larval fish that swam in the swim chamber. Developmental stages (according to Yi et al. 1988a; translated in Chapman 2006) were also assessed and daily means were recorded (means were based on the numerical stage; i.e. 37-48). Due to possible mismatch in lengths and swimming speeds, mean values for total length were used to calculate the relative maximum swimming speed (maximum swimming speed per total length) using the formula:

$\mathrm{U}_{\text {maxrel }}=\mathrm{U}_{\max } / \mathrm{TL}$, where $\mathrm{TL}=$ mean total length (TL; in $\mathrm{cm}$ ) and $\mathrm{U}_{\text {maxrel }}$ is the maximum speed in body lengths per second.

Daily means of $U_{\text {maxrel and }} U_{\max }$ were also computed. Larvae were collected, euthanized with an overdose of MS-222 (tricaine methanesulfonate), staged, and measured following the swimming performance test.

\section{Regressions}

Linear regressions were performed for each species based on a) days post hatch (DPH) vs daily mean maximum speed $\left(\mathrm{U}_{\max } ; \mathrm{cm} / \mathrm{s}\right)$, b) daily mean developmental stage (as described in Yi et al. 1988a and Chapman 2006) vs daily mean $U_{\max }$, and c) daily mean total length $(\mathrm{mm})$ vs daily mean $\mathrm{U}_{\max }$. Equations, $\mathrm{p}$ values, and $\mathrm{R}^{2}$ values are reported.

\section{Results}

\section{Routine swimming speed}

After gas bladder inflation, vertical swimming speed decreased with ontogeny and horizontal swimming speed first increased and then decreased (Figure 1). Mean initial vertical swimming speeds between hatch and gas bladder emergence in grass carp larvae were $2.37 \pm 1.23 \mathrm{~cm} / \mathrm{s}$ (SD), (range $0.008-11.99 \mathrm{~cm} / \mathrm{s}$, $\mathrm{n}$ (number of movements) = 798) and bighead carp larvae had mean speeds of $2.73 \pm 1.16 \mathrm{~cm} / \mathrm{s}$ (range $=0.03-20.47 \mathrm{~cm} / \mathrm{s}, \mathrm{n}$ =907). Following gas bladder inflation (developmental stage 38), grass carp had a mean horizontal swimming speed of $0.66 \pm 0.77 \mathrm{~cm} / \mathrm{s}$ (range $=0.000024-30.72 \mathrm{~cm} / \mathrm{s}, \mathrm{n}=4936$ ), while bighead carp larvae had a mean horizontal swimming velocity of $0.996 \pm 0.516 \mathrm{~cm} / \mathrm{s}$ (range $=0.00005-19.44 \mathrm{~cm} / \mathrm{s}, \mathrm{n}=5818$ ). Silver carp had initial vertical swimming speed of $1.83 \pm 1.08 \mathrm{~cm} / \mathrm{s}$ (range $=0.025-20.6 \mathrm{~cm} / \mathrm{s}, \mathrm{n}=470$ ), and horizontal swimming speed of $1.20 \pm 0.70 \mathrm{~cm} / \mathrm{s}$ (range $=0.07-27.9 \mathrm{~cm} / \mathrm{s}, \mathrm{n}=2036)$. For all species, downward velocity was up to twice as fast as upwards velocity during the vertical swimming period prior to gas bladder inflation (Figure 1). After gas bladder inflation and the onset of primarily horizontal swimming, downwards velocity was similar to upwards velocity. 
301

302

303

304

305

306

307

308

309

310

311

312

313

314

315

316

317

318

319

320

321

322

323

324

325

326

327

328

329

330

331

332

333

334

335

336

337

338

339

340

341

342

\section{Maximum swimming speed}

For all species, absolute maximum swimming speed generally increased with ontogeny, while the relative maximum swimming speed had an initial increase between hatching and yolk absorption, with a subsequent decrease following development of the second gas bladder chamber (Figure 2). At 4 days post hatch (DPH; mean developmental stage (DS) = 37.8), mean absolute maximum swimming speed was $2.56 \pm 0.67$ (SD) $\mathrm{cm} / \mathrm{s}$ for silver carp, $11.34 \pm 5.18 \mathrm{~cm} / \mathrm{s}$ (DS = 37) for grass carp (DS = 38), and $11.27 \pm 3.8 \mathrm{~cm} / \mathrm{s}$ for bighead carp (DS = 37) and increased to $39.08 \pm 7.88 \mathrm{~cm} / \mathrm{s}$ for silver carp (46 DPH, DS 47.8), 57.58 $\pm 16.00 \mathrm{~cm} / \mathrm{s}$ for grass carp (28 DPH; DS $=48$ ), and $45.41 \pm 10.94 \mathrm{~cm} / \mathrm{s}$ for bighead carp (36 DPH; DS = 48). Corresponding shifts in relative speed were evident, going from $16.53 \pm$ $0.91 \mathrm{TL} / \mathrm{s}(9 \mathrm{DPH}$; DS = 39.2) to $12.95 \pm 2.57 \mathrm{TL} / \mathrm{s}(61 \mathrm{DPH}$; DS = 48) in silver carp, $27.82 \pm$ $4.03 \mathrm{TL} / \mathrm{s}$ (7 DPH; DS = 39.3) to $17.32 \pm 5.96 \mathrm{TL} / \mathrm{s}(21 \mathrm{DPH}$; DS = 47.05) in grass carp, and $28.94 \pm 7.69 \mathrm{TL} / \mathrm{s}(7 \mathrm{DPH} ; \mathrm{DS}=38.45)$ to $14.49 \pm 3.49 \mathrm{TL} / \mathrm{s}(36 \mathrm{DPH}$; DS = 48) in bighead carp. For silver carp, there was very little variation in total length during the first two-week measurement period, and limited developmental changes, but bighead carp and grass carp had faster growth and developmental rates (Figure 3). After the switch to pond reared fish, growth was initially strong, but decreased substantially by the end of testing.

\section{Regressions}

Days post hatch was the regression with the best fit value for bighead carp and grass carp, and stage had the best fit value for silver carp (Table 2). Stage had the lowest fit value for bighead carp and grass carp. Grass carp and silver carp had very good fit with all parameters, and bighead carp fit well with 2 out of 3 parameters.

\section{Discussion}

Increases in maximum speeds over ontogeny in grass carp and bigheaded carps are indicative of increasing swimming capability, while decreases in routine swimming speed show behavioral changes that affect dispersal potential. Larval fish are likely to use a strategy of "behavioral drifting" (Hogan and Mora 2005), in which the larvae choose not to swim, and instead drift with the current. This strategy is consistent with the downstream drift that has been suggested by ichthyoplankton sampling (Yi et al. 1988b). Many studies on the early life history of grass carp and bigheaded carps (e.g. Verigin et al. 1978) postulated that larvae were carried into nursery areas by currents; however, these data, as well as the collections by Deters et al. (2013), indicate that larvae are not helpless residents of the drift, but have some capability to select their location in the river, or to leave the main channel and select nursery habitats. Other cyprinids, such as silver bream and roach, have also been shown to select nursery habitats (Copp 1997). Similar to marine fish larvae (Leis 2007), describing freshwater fish larval stages as "ichthyoplankton" is something of a misnomer. These data show that larval fish have substantial ability to swim and control 
343 position within a water column, which can have substantial effects on their ultimate drift 344 distance and settlement locations.

345

346 Differences among species in growth and developmental rates were evident over the 347 course of the experiment. During the first two weeks of each trial, all fish were reared in 348 tanks. Although fed twice daily with an appropriate living food, silver carp exhibited very little growth while being reared in tanks, and the pond-raised fish had higher growth rates than tank-reared fish. Silver carp developmental rates in tanks were also slower than predicted by developmental models (George and Chapman 2013), and slower in development than pond-reared fish of the same brood. We do not know the reason for this slower development, but we speculate that it may have been due to crowding or food scarcity. The other two species showed faster development and growth under similar conditions, and were similar to model predictions of developmental rate (George and Chapman 2015). Silver carp in tanks did not advance past the notochord tip lifting stage (stage 41) during those first two weeks, and bighead and grass carp larvae in tanks achieved stage 43 (two chamber gas bladder) in a similar interval. If the silver carp larvae were of lower condition (evidenced by slower growth and development) than the bighead carp or grass carp larvae in our experiments, it may have been responsible for the somewhat slower swimming speeds of the silver carp larvae. Leis et al. 2011 suggest that much of the variation in swimming performance of larval labrids might be explained by variation in condition. Bighead carp larvae were also substantially larger at most developmental stages than silver carp or grass carp larvae. This may be due to maternal effects from the larger female carp used for spawning (2-3 times larger than silver or grass carp females). The difference between growth rates and developmental rates shows that some fish can be comparatively advanced while still at a small size, and thus size is not necessarily predictive of swimming speed. Developmental stages from Yi et al. 1988 are based on development of structures (such as fins, gills, eyes, etc.), and structures such as gas bladder or fin development have large effects on swimming capacity. Especially for silver carp at these stages in early life history, developmental stage has greater effects on swimming capability than size.

Temperature affects both fish development rate and the density and physical properties of water. Swimming performance and other physiological factors are also influenced by temperature (Fuiman 1986; Hunt von Herbing 2002). Fuiman and Batty 1997 found that small Atlantic herring larvae were affected by viscosity, but not temperature, while larger larvae were affected by both temperature and viscosity. However, the temperature range at which we tested carp larvae was relatively small (and in the range where density and viscosity are much less affected by temperature), with minimal effects on viscosity and density. In general, it would be comparable to temperatures found during natural spawning events. This should be expanded on in future experiments to determine the role that abiotic factors can play in larval swimming capacity. Other water quality parameters, such as $\mathrm{pH}$ and turbidity, can also influence larval swimming behavior (Rieger and Summerfelt 1997; Utne-Palm 2004; Chan et al. 2015) and should also be considered for 
422

423

424

425

426

427

modelling purposes.

Larvae will obviously interact with their physical environment in different ways than eggs, and hydraulic conditions that are favorable to egg suspension may have different consequences for larval dispersal. Murphy and Jackson (2013), determined that eggs would settle at mean current velocities of $15-25 \mathrm{~cm} / \mathrm{s}$, and maximum swimming velocities of larval grass carp and bigheaded carps are within that range or greater at most tested ages. Using the FluEgg model to evaluate settlement of water-hardened silver carp eggs showed that eggs would settle at mean current velocities of $16 \mathrm{~cm} / \mathrm{s}$ (Garcia et al. 2015a). Laboratory experiments were performed using artificial surrogates for silver carp eggs with flows ranging from $4-40 \mathrm{~cm} / \mathrm{s}$ (shear velocities $0.2-1.6 \mathrm{~cm} / \mathrm{s}$ ) and demonstrated egg suspension at mean velocities as low as $7 \mathrm{~cm} / \mathrm{s}$ (shear velocity of $0.4 \mathrm{~cm} / \mathrm{s}$; Garcia et al. $2015 \mathrm{~b}$ ). These mean velocities are within the range of routine swimming speeds for grass carp and bigheaded carp larvae at all tested ages.

In rivers that have comparable flow conditions (mean velocity, water depth, and shear velocity), flow conditions that are conducive to egg suspension would also be conducive to larval dispersal, and larvae would have some capability to control depth and position within the water column. Many rivers in the central United States in which carp are found, such as the Illinois River, have flow velocities that range between 15-92 cm/s (USGS gage data), depending on location, discharge and other physical factors. At the lower end of this range, larval swimming abilities could have a large effect on their dispersal potential. In faster velocity rivers (such as the Missouri River, where mean velocity regularly exceeds $100 \mathrm{~cm} / \mathrm{s}$ and can be as high as $280 \mathrm{~cm} / \mathrm{s}$ in the thalweg; Armstrong et al. 2014), the ability of larvae to control depth and position is unknown, and could be impeded by higher shear velocities and macroturbulence, making it difficult for larvae to move into nursery habitats. However, collections from tributaries of the Missouri River (Deters et al. 2013) show that many larvae do manage to leave the high velocity areas.

Although exact habitat requirements are unknown, it is thought that Asian carp use shallow, low-velocity nursery habitat, generally in tributaries, backwaters, channelmargins, or behind wing-dikes (Kolar et al. 2007). Nursery habitat is often open water, although larval Asian carp have also been found in areas with large woody debris (C. Hayer, personal communication). Surveys by Deters et al. (2013) on the Missouri River showed that Asian carp larvae past stage 40 (based on the developmental stages of Yi et al. 1988) were seldom collected in the mainstem river, presumably because they had moved into preferred off-channel nursery habitats where fish of those stages were captured, but possibly because some fish of that stage which remained in the drift selected unsampled portions of the river or avoided the sampling gear. As in other studies (e.g. Lenaerts et al. 2015), collection of larvae from the Missouri River and its tributaries has been primarily from near-surface tows (Deters et al. 2013), which have contained abundant larvae of developmental stages 31-39 (hatching through yolk sac absorption; based on Yi et al. 
428 1988). While vertical distribution of larvae in the water column is unknown, this shows 429 that at least a portion of larvae can use the fastest currents near the surface, potentially 430 expanding their downstream dispersal range. Expanding larval sampling protocols to 431 encompass multiple depths could provide further insight into larval distribution and depth 432 preferences.

433

434 Entrainment of grass carp and bigheaded carp due to barge traffic is a substantial concern 435 with regards to spreading larvae and small juveniles into new ranges (Davis et al. 2016). 436 Gaps between barges can allow entrainment, retention, and transport of eggs and small fish 437 through river systems. In trials, juvenile fish were transported up to $15.5 \mathrm{~km}$ upstream, 438 which could move these invasive species past control barriers. While the juveniles in that 439 study did show the potential for entrainment within the gaps between barges, similar 440 studies were not pursued with larvae, although it was suggested that eggs and larvae could 441 be entrained from greater distances than the juveniles studied, and the lateral distribution 442 of larval grass carp or bigheaded carp throughout a channel could put them at greater risk 443 of entrainment than juvenile fish, which are usually concentrated in off-channel habitats. 444 Understanding the maximum speed that larvae can achieve can give some indication of the 445 ability of these organisms to resist entrainment or to selectively remain in the interstices 446 between barges. Speed was variable during these trials, ranging from $1.9-3 \mathrm{~km} / \mathrm{h}$ in one 447 trial and $0.3-0.6 \mathrm{~km} / \mathrm{hr}$ in another $(1 \mathrm{~km} / \mathrm{h}$ is approximately $27.8 \mathrm{~cm} / \mathrm{s}$, which is within the 448 maximum swimming speed of some of these larvae).

449

450

451

452

453

The swimming ability of larval reef fish tends to decrease at settlement (Leis et al. 2011), and many larval fish have considerably larger relative swimming speeds than adult fish (Muller 2008). However, absolute swimming speed increases with ontogeny, which allows larvae to move out of the main channel and into nursery areas. Experiments in a

454 laboratory flume (Prada et al. In review) show that larval swimming speeds are dependent

455

456

457 on developmental state and water velocity. Especially during the settlement period, the swimming capability of larvae must be strong enough to move within the flow field and into low velocity areas. Hydraulic conditions surrounding river confluences can be very

458

459 different from channel conditions (average flow velocity at bankfull conditions can be 1.6 times higher at the confluence than in the tributaries; Roy et al. 1988), and larvae must

460

461 have the capacity to either select swimming paths of lower velocity or manage potentially higher velocity shear flows.

462

\section{Conclusions}

464 Larval dispersal from hatching location to nursery habitat can be complex and is dependent 465 upon a number of factors including habitat availability, travel distance, temperature, and 466 hydraulic conditions. Combining information on swimming speed with detailed hydraulic 467 and habitat data for a particular river reach should allow the refinement of models to 468 establish locations where grass carp and bigheaded carp larvae are capable of leaving the 469 river for backwater nursery habitat. Pest management strategies can be strategically 
470

471

472

473

474

475

476

477

478

479

480

481

482

483

484

485

486

487

488

489

490

491

492

493

494

495

496

497

498

499

500

501

502

503

504 505

506

employed at those locations, by engineering habitat to be attractive to settlement whereby management and control strategies for larvae could be employed or areas could be designed to be unattractive for settlement, thus preventing recruitment at certain sites. Further studies on swimming behavior in response to current, nursery habitat requirements, and attractants to nursery habitat are necessary to determine recruitment potential in rivers, which can then be used to develop control and pest management strategies focusing on the reduction of recruitment.

\section{Acknowledgements}

We thank C. Byrd, J. Candrl, J. Carroll, T. Kobermann, and P. Kroboth for their assistance. J. Deters designed and built a frame for lighting. E. Little, E. Scott, and H. Puglis provided endurance chambers and set-up assistance. All product and trade names are for descriptive purposes only and do not imply endorsement by the U.S. Government.

\section{Literature Cited}

Armstrong, D.J., Wilkison, D.H., and Norman, R.D., 2014, A velocimetric survey of the Lower Missouri River from river mile 492.38 to 290.20, July-October 2011 and July 2012: U.S. Geological Survey Scientific Investigations Report 2013-5197, 34 p.,

Beamish, F.W.H., 1978, Swimming capacity, in Hoar, W.S., and Randall, D.J., eds., Fish Physiology: New York, Academic Press, p. 101-183.

Byrd, C.G., Chapman, D.C., Pherigo, E.K., and Jolley, J.C., in review, Tag retention and survival of juvenile bighead carp implanted with an acoustic tag at three temperatures.

Chan, K.Y.K., Garcia, E., and Dupont, S., 2015, Acidification reduced growth rate but not swimming speed of larval sea urchins: Scientific Reports 5:9764

Chapman, D.C., and George, A.E., 2011, Developmental rate and behavior of early life stages of bighead and silver carp: U.S. Geological Survey Scientific Investigations Report 20115076, $11 \mathrm{p}$.

Chapman, D.C., and Wang, N., 2006, Early development of four cyprinids native to the Yangtze River, China: U.S. Geological Survey Data Series 239, 51 p. 
507 Copp, G.H., 1997, Microhabitat use of fish larvae and $0(+)$ juveniles in a highly regulated 508 section of the River Great Ouse: Regulated Rivers: Research and Management 13(3):267509276.

510

511 Davis, J.J., Jackson, P.R., Engel, F.L., LeRoy, J.Z., Neeley, R.N., Finney, S.T., and Murphy, E.A., 512 2016, Entrainment, retention, and transport of freely swimming fish in junction gaps 513 between commercial barges operating on the Illinois Waterway: Journal of Great Lakes 514 Research 42(4):837-842.

515

516 Faillettaz, R., Durand, E., Paris, C.B., Koubbi, P., and Irisson, J., 2018, Swimming speeds of 517 Mediterranean settlement-stage fish larvae nuance Hjort's aberrant drift hypothesis:

518 Limnology and Oceanography 63:509-523.

519

520

521

522

523

524

525

526

527

528

529

530

531

532

533

534

535

536

537

538

539

540

541

542

543

544

Fisher, R., and Leis, J.M., 2010, Swimming speeds in larval fishes: from escaping predators to the potential for long distance migration, in Domenici, P., and Kapoor, B.G., eds., Fish locomotion: An eco-ethological perspective: Enfield, New Hampshire, Science Publishers, p. 333-373.

Fuiman, L.A., 1986, Burst-swimming performance of larval zebra danios and the effects of diel temperature fluctuations: Transactions of the American Fisheries Society 115(1):143148.

Fuiman, L.A., and Batty, R.S., 1997, What a drag it is getting cold: partitioning the physical and physiological effects of temperature on fish swimming: Journal of Experimental Biology 200:1745-1755.

Garcia, T., Jackson, P.R., Murphy, E.A., Valocchia, A.J., and Garcia, M.H., 2013, Development of a Fluvial Egg Drift Simulator to evaluate the transport and dispersion of Asian carp eggs in rivers: Ecological Modelling 263:211-222.

Garcia, T., Murphy, E.A., Jackson, P.R., and Garcia, M.H., 2015a, Application of the FluEgg model to predict transport of Asian carp eggs in the Saint Joseph River (Great Lakes tributary): Journal of Great Lakes Research 41:374-386.

Garcia, T., Zuniga Zamalloa, C., Jackson, P.R., Murphy, E.A., Garcia, M.H. 2015b, A laboratory investigation of the suspension, transport, and settling of silver carp eggs using synthetic surrogates. PLoS One 10(12): e0145775. 
545 George, A.E., and Chapman, D.C., 2013, Aspects of embryonic and larval development in 546 bighead carp Hypophthalmichthys nobilis and silver carp Hypophthalmichthys molitrix: PLoS 547 One 8(8):e73829.

548

549

550

551

552

553

554

555

556

557

558

559

560

561

562

563

564

565

566

567

568

569

570

571

572

573

574

575

576

577

578

579

580

581

582

583

George, A.E., and Chapman, D.C., 2015, Embryonic and larval development and early behavior in grass carp, Ctenopharyngodon idella: implications for recruitment in rivers: PLoS One 10(3): e0119023.

Hogan, J.D., and Mora, C., 2005, Experimental analysis of the contribution of swimming and drifting to the displacement of reef fish larvae: Marine Biology 147: 1213-1220.

Hoover, J.J., Collins, J.A., Katzenmeyer, A.W., and Killgore, K.J., 2016, Swimming performance of adult Asian carp: field assessment using a mobile swim tunnel: U.S. Army Engineer Research and Development Center ERDC/TN ANSRP-16-1, 16 p.

Hoover, J.J., Southern, L.W., Katzenmeyer, A.W., and Hahn, N.M., 2012, Swimming performance of bighead carp and silver carp: methodology, metrics, and management applications: U.S. Army Engineer Research and Development Center ERDC/TN ANSRP-12$3,12 \mathrm{p}$.

Hoover, J.J., Zielinski, D.P., and Sorensen, P.W., 2017, Swimming performance of adult bighead carp Hypophthalmichthys nobilis (Richardson, 1845) and silver carp H. molitrix (Valenciennes, 1844): Journal of Applied Ichthyology 33: 54-62.

Hunt von Herbing, I., 2002, Effects of temperature on larval fish swimming performance: the importance of physics to physiology: Journal of Fish Biology 61(4):865-876.

Kocovsky, P.M., Chapman, D.C., and McKenna, J.E., 2012, Thermal and hydrologic suitability of Lake Erie and its major tributaries for spawning of Asian carps: Journal of Great Lakes Research 38:159-166.

Krykhtin, M.L., and Gorbach, E.I., 1981, The breeding ecology of the grass carp Ctenopharyngodon idella (Val.) and silver carp Hypophthalmichthys molitrix (Val.) in the Amur River basin: Voprosy Ikhtiologii 21(2):317-330.

Kolar, C.S., Chapman, D.C., Courtenay, W.R., Housel, C.M., Williams, J.D., and Jennings, D.P., 2007, Bigheaded carps: a biological synopsis and risk assessment: Bethesda, Maryland, American Fisheries Society, 204 p. 
584 Komarov, V.T., 1971, Speeds of fish movement: Vestnik zoologii 4:67-71.

585

586

587

588

589

590

591

592

593

594

595

596

597

598

599

600

601

602

603

604

605

606

607

608

609

610

611

612

613

614

615

616

617

618

619

620

621

Lechner, A., Keckeis, H., Schludermann, E., Humphries, P., McCasker, N., and Tritthart, M., 2014, Hydraulic forces impact larval fish drift in the free flowing section of a large European river: Ecohydrology 7:648-658.

Leis, J.M., 2007, Behaviour as input for modelling dispersal of fish larvae: behaviour, biogeography, hydrodynamics, ontogeny, physiology and phylogeny meet hydrography: Marine Ecology Progress Series 347:185-193.

Leis, J.M., Hay, A.C., and Gaither, M.R., 2011, Swimming ability and its rapid decrease at settlement in wrasse larvae (Teleostei: Labridae): Marine Biology 158:1239-1246.

Muller, U.K., 2008, Swimming and muscle, in Finn, R.N., and Kapoor, B.G., eds., Fish Larval Physiology: Enfield, New Hampshire, Science Publishers Inc., p. 523-549.

Murphy, E. A., Garcia, T., Jackson, P.R., and Duncker, J.J. 2016. Simulation of hypothetical Asian carp egg and larvae development and transport in the Lockport, Brandon Road, Dresden Island, and Marseilles pools of the Illinois Waterway by use of the fluvial egg drift simulator (FluEgg) model. U.S. Geological Survey, Open File Report 2016-1011.

Murphy, E.A., and Jackson, P.R., 2013, Hydraulic and water-quality data collection for the investigation of Great Lakes tributaries for Asian carp spawning and egg-transport suitability: U.S. Geological Survey Scientific Investigations Report 2013-5106, 30 p.

Newbold, L.K., Shi, X., Hou, D., and Kemp, P.S., 2016, Swimming performance and behaviour of bighead carp (Hypophthalmichthys nobilis): application to fish passage and exclusion criteria: Ecological Engineering, v. 95, p. 690-698.

Peck, M.A., Buckley, L.J., and Bengtson, D.A., 2006, Effects of temperature and body size on the swimming speed of larval and juvenile Atlantic cod (Gadus morhua): implications for individual-based modelling: Environmental Biology of Fishes 75: 419-429.

Piper R.G., McElwain I.B., Orme L.E., McCraren J.P., Fowler L.G., and Leonard, A.R. 1982, Fish hatchery management. Washington, D.C.: U.S. Fish and Wildlife Service.

Prada, A.F., George A.E., Stahlschmidt, B.H., Chapman, D.C., and Tinoco, R.O., (in review), Survival and drifting patterns of grass carp eggs and larvae in response to interactions with 
622 flow and sediment in a laboratory flume.

623

624 Rieger, P.W., and Summerfelt, R.C., 1997, The influence of turbidity on larval walleye,

625 Stizostedion vitreum, behavior and development in tank culture: Aquaculture 159:19-32.

626

627

Roy, A.G., Roy, R., and Bergeron, N., 1988, Hydraulic geometry and changes in flow velocity

628 at a river confluence with coarse bed material: Earth Surface Processes and Landforms

629 13(7):583-598.

630

Schludermann, E., Tritthart, M., Humphries, P., and Keckeis, H., 2012, Dispersal and

631 retention of larval fish in a potential nursery habitat of a large temperate river: an

632 experimental study: Canadian Journal of Fisheries and Aquatic Sciences 69:1302-1315.

633

Soin, S.G., and Sukhanova, A.I., 1972, Comparative morphological analysis of the

635 development of the grass carp, the black carp, the silver carp and the bighead (Cyprinidae).

636 Journal of Ichthyology 12(1):67-71.

637

638

Utne-Palm, A.C., 2004, Effects of larvae ontogeny, turbidity, and turbulence on prey attack

639 rate and swimming activity of Atlantic herring larvae: Journal of Experimental Marine

640

641

642 Biology and Ecology 310:147-161.

643

Videler, J.J., and Wardle, C.S., 1991, Fish swimming stride by stride: speed limits and endurance: Reviews in Fish Biology and Fisheries 1: 23-40.

644

Videler, J.J., 1993, Fish Swimming, Chapman and Hall, 260 p.

646

Yi, B., Liang, Z., Yu, Z., Lin, R., and He, M., 1988a, A comparative study on the early

648 development of grass carp, black carp, silver carp, and big head of the Yangtze River, in Yi, B., Yu, Z., and Liang, Z., eds., Gezhouba water control project and four famous fishes in the Yangtze River, China: Wuhan, China, Hubei Science and Technology Press, p. 69-135.

651

652

653

654

655

656

657

Yi, B., Yu, Z., Liang, Z., Sujuan, S., Xu, Y., Chen, J., He, M., Liu, Y., Hu, Y., Deng, Z., Huang, S., Sun, J., Liu, R., and Xiang, Y., 1988b, The distribution, natural conditions, and breeding production of the spawning ground of four famous freshwater fishes on the main stream of the Yangtze River., in Yi, B., Yu, Z., and Liang, Z., eds., Gezhouba Water Control Project and four famous fishes in Yangtze River: Wuhan, China, Hubei Science and Technology Press, p. 658 
Table $\mathbf{1}$ (on next page)

Camera settings used to capture routine swimming speeds of larval carps. 
1

2 Table 1. Camera settings used to capture routine swimming speeds of larval carps.

\begin{tabular}{|l|l|l|l|l|l|l|l|}
\hline Species & $\begin{array}{l}\text { Shutter } \\
\text { speed }\end{array}$ & $\begin{array}{l}\text { ISO } \\
\text { setting }\end{array}$ & Aperture & $\begin{array}{l}\text { Focal } \\
\text { Length }\end{array}$ & $\begin{array}{l}\text { Distance } \\
\text { from tank }\end{array}$ & $\begin{array}{l}35 \mathrm{~mm} \text { focal } \\
\text { length }\end{array}$ & $\begin{array}{l}\text { Frame } \\
\text { rate }\end{array}$ \\
\hline Silver carp & $1 / 160 \mathrm{sec}$ & 1000 & $\mathrm{f} / 29$ & $34 \mathrm{~mm}$ & $200 \mathrm{~mm}$ & $51 \mathrm{~mm}$ & $2-3 \mathrm{fps}$ \\
\hline Bighead carp & $1 / 250 \mathrm{sec}$ & 1000 & $\mathrm{f} / 29$ & $35 \mathrm{~mm}$ & $200 \mathrm{~mm}$ & $52 \mathrm{~mm}$ & $6-7 \mathrm{fps}$ \\
\hline Grass carp & $1 / 250 \mathrm{sec}$ & 1000 & $\mathrm{f} / 29$ & $35 \mathrm{~mm}$ & $200 \mathrm{~mm}$ & $52 \mathrm{~mm}$ & $6-7 \mathrm{fps}$ \\
\hline
\end{tabular}

3 


\section{Table 2 (on next page)}

Results of linear regressions for each species.

Equations and $R^{2}$ values are given for days post hatch (DPH), mean length ( $T L ;$ in $m m$ ), and mean developmental stage (Yi et al. 1988a stages) in relation to mean maximum speed $\left(U_{\max } ;\right.$ in $\left.\mathrm{cm} / \mathrm{s}\right)$. $P$ values for all regressions were less than 0.0001 . 
1 Table 2. Results of linear regressions for each species. Equations and $R^{2}$ values are given for 2 days post hatch (DPH), mean length (TL; in $\mathrm{mm}$ ), and mean developmental stage (Yi et al. 1988a

3 stages) in relation to mean maximum speed $\left(U_{\text {max }} ;\right.$ in $\left.\mathrm{cm} / \mathrm{s}\right)$. $P$ values for all regressions were 4 less than 0.0001.

Bighead carp

DPH

$$
\mathrm{U}_{\max }=0.73 * \mathrm{DPH}+16.60
$$$$
\mathrm{R}^{2}=0.8915
$$

Length

$$
\begin{aligned}
& \mathrm{U}_{\max }=1.05^{*} \mathrm{TL}+14.17 \\
& \mathrm{R}^{2}=0.8579
\end{aligned}
$$

Stage

$$
\begin{aligned}
& \mathrm{U}_{\max }=2.07 * \text { Stage }-58.90 \\
& \mathrm{R}^{2}=0.7753
\end{aligned}
$$

\section{Grass carp}

$\mathrm{U}_{\max }=1.68 * \mathrm{DPH}+7.45$

$R^{2}=0.9612$

$\mathrm{U}_{\max }=1.72 * \mathrm{TL}+6.75$

$\mathrm{R}^{2}=0.8944$

$\mathrm{U}_{\max }=3.39 *$ Stage -114.25

$\mathrm{R}^{2}=0.8699$

\section{Silver carp}

$\mathrm{U}_{\max }=0.75^{*} \mathrm{DPH}+4.07$

$R^{2}=0.8894$

$\mathrm{U}_{\max }=1.26 * \mathrm{TL}+1.86$

$\mathrm{R}^{2}=0.9121$

$\mathrm{U}_{\max }=3.71 *$ Stage -134.56

$R^{2}=0.9509$ 


\section{Figure 1}

Routine swimming speeds of bighead carp, silver carp and grass carp larvae

Square root transformed daily vertical and horizontal routine swimming speeds $(\mathrm{cm} / \mathrm{s})$ for bighead carp (BHC), grass carp (GCP), and silver carp (SVC) larvae are shown by days post hatch (DPH). Vertical movement is separated into upward and downward movement, while lateral or horizontal movement considers both left and rightward movement.

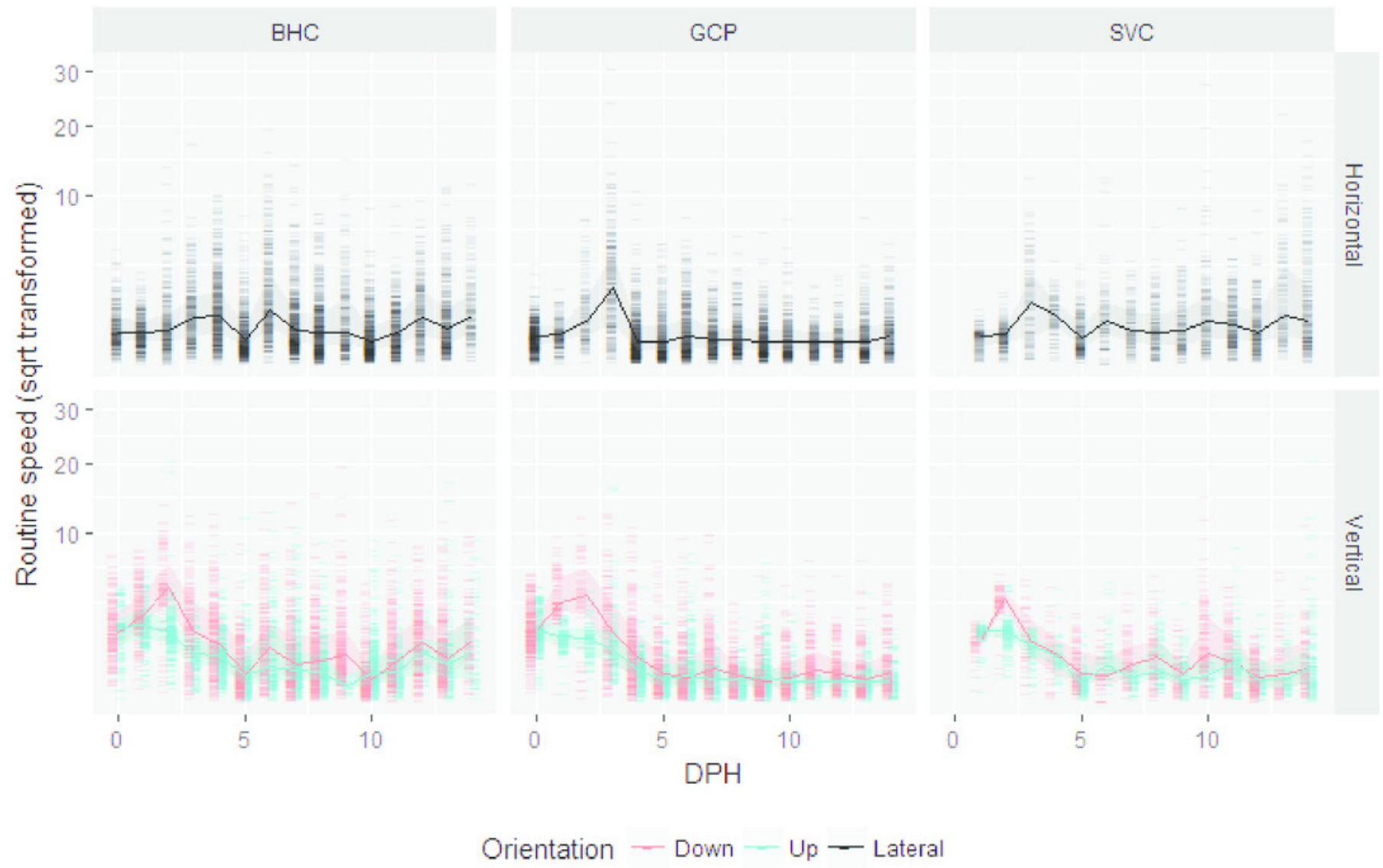


Figure 2

Maximum swimming speed of larval bighead, silver, and grass carp

Maximum speeds of larval bighead carp $(a, d)$, grass carp $(b, e)$, and silver carp $(c, f)$ over time.

Maximum speed is given in actual (cm/s; a-c) and relative (total length/s; d-f) speeds. Initial measurements for all species was at developmental stage 38 (Gas bladder inflation; Yi et al. 1988), and vertical lines indicate stage 40 (caudal tip lifting for grass carp and silver carp, yolk sac absorption for bighead carp; Yi et al. 1988). Final measurements were taken at juvenile stage (stage 48, Yi et al. 1988).

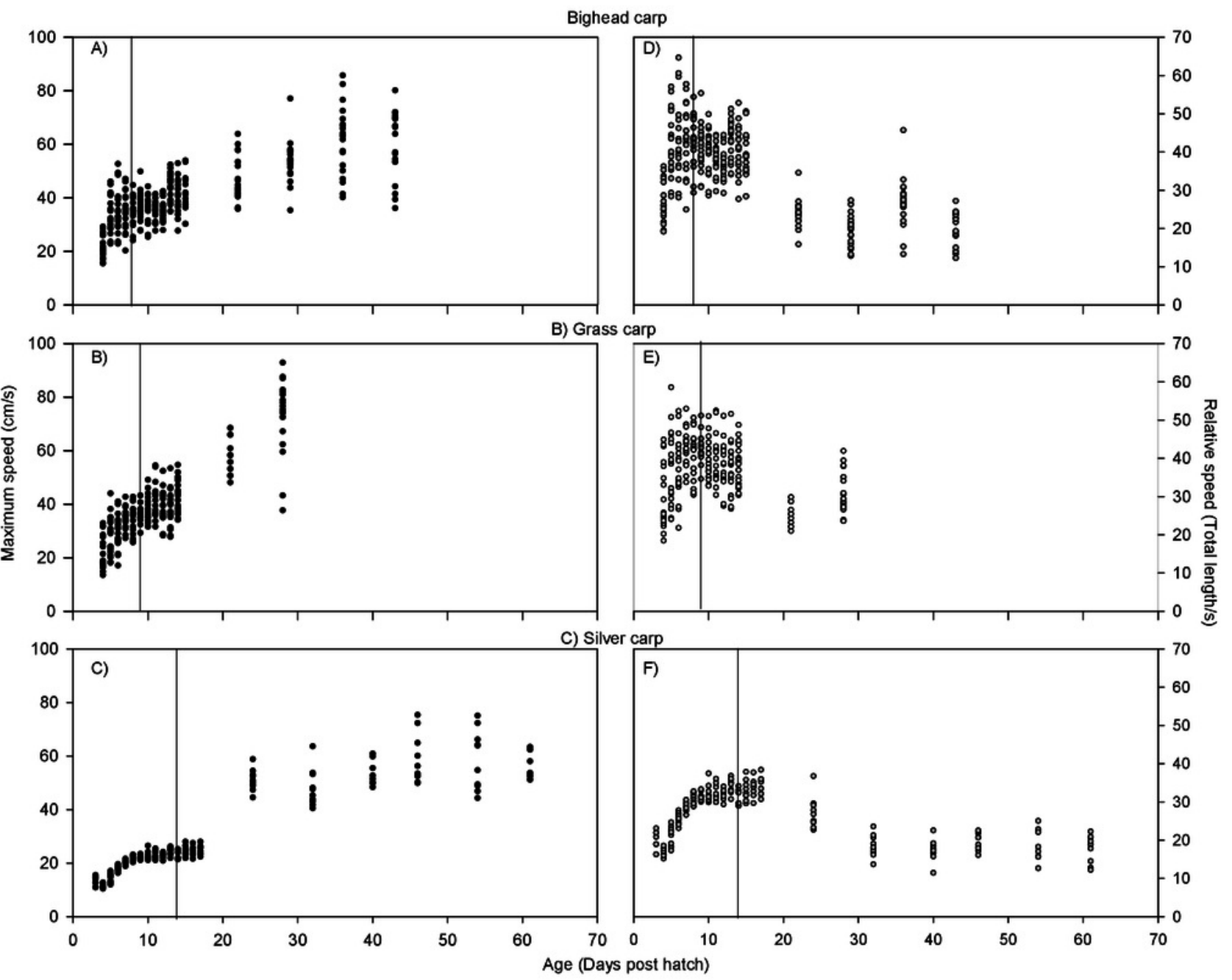




\section{Figure 3}

Total length of larval bighead carp, silver carp, and grass carp

Total length of larval bighead carp (BHC), grass carp (GSCP), and silver carp (SVC) over time (Days post hatch; DPH). The blue line represents mean TL. All measurements earlier than 20 $\mathrm{DPH}$ are on laboratory-raised fish, measurements later than $20 \mathrm{DPH}$ were pond-raised fish. 


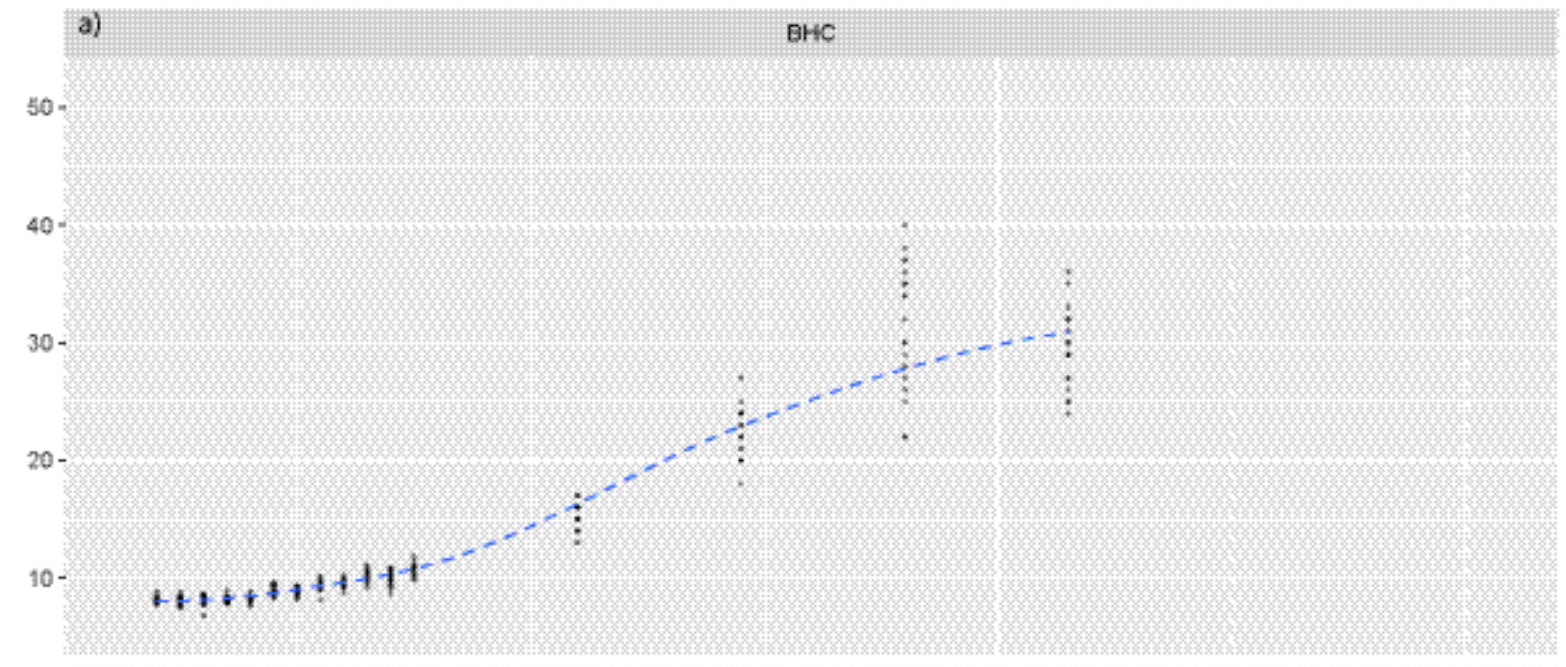
b)
GSCP
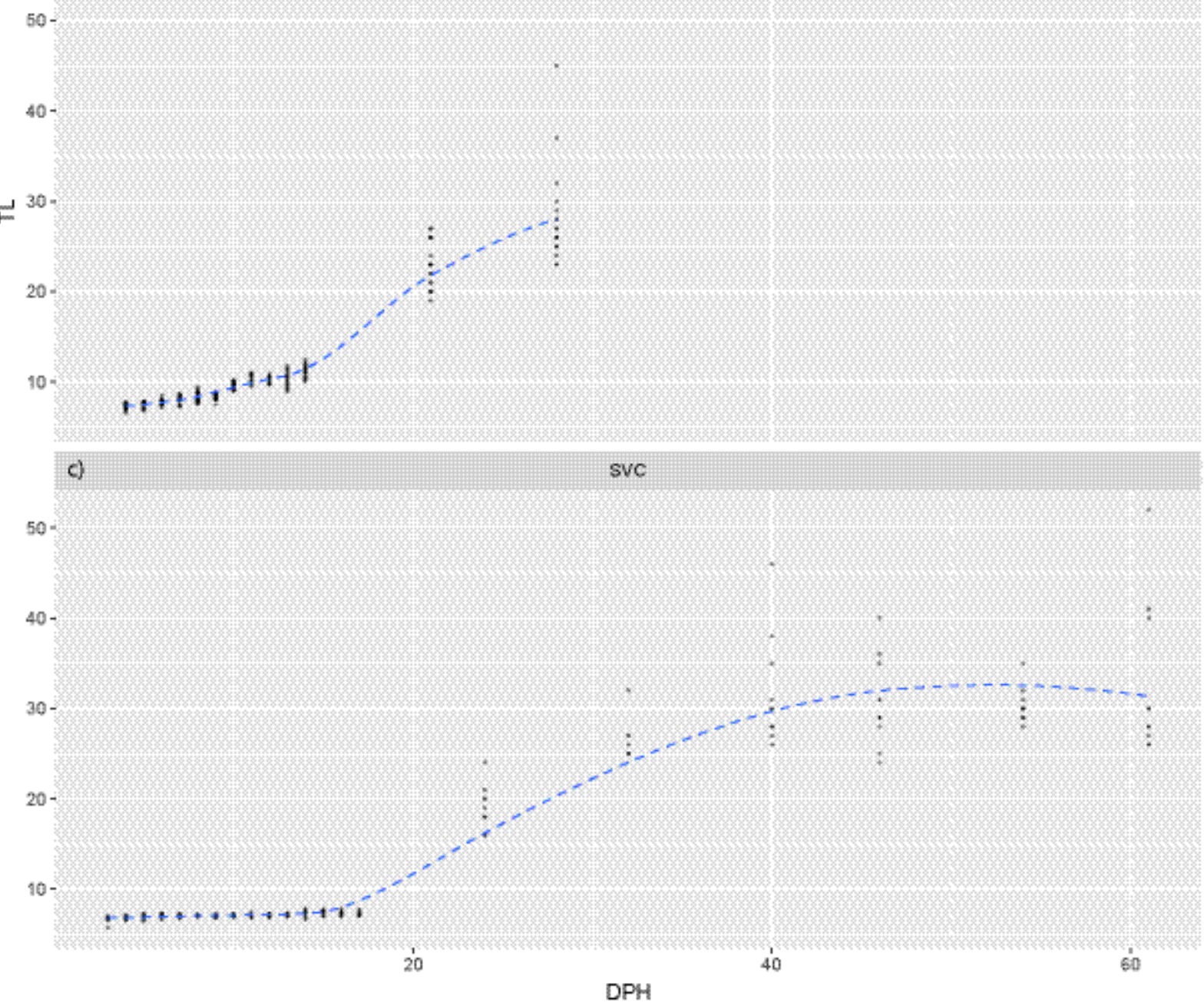